\title{
PERSPECTIVAS SOBRE A VALORIZAÇÃO DA GEODIVERSIDADE E A GEOCONSERVAÇÃO NA
} AMAZÔNIA

\author{
Celina Marques do Espirito Santo \\ Universidade Federal do Amapá (UNIFAP) \\ Docente do curso de Bacharelado em Geografia \\ espiritosantocelina@gmail.com \\ Milena Marília Nogueira de Andrade \\ Universidade Federal Rural da Amazônia (UFRA \\ Docente do curso de Eng. Ambiental e Energias Renováveis \\ milena.andrade@ufra.edu.br \\ Jucilene Amorim Costa \\ Universidade Federal do Amapá (UNIFAP) \\ Docente do Programa de Pós-Graduação em Geografia \\ jucilene22@bol.com.br \\ Danusa da Silveira Machado \\ Universidade Federal do Amapá (UNIFAP) \\ Discente do curso de Bacharelado em Geografia \\ danusa.ap@hotmail.com \\ Walmira Ferreira Lopes \\ Universidade Federal Rural da Amazônia (UFRA) \\ Discente do curso de Eng. Ambiental e Energias Renováveis \\ walmira.wf@gmail.com
}

\begin{abstract}
RESUMO
As discussões sobre a valorização da geodiversidade têm ganhado destaque no cenánio brasileiro e, mais recentemente, na Amazônia. Assim, o presente artigo analisa algumas iniciativas que permitem a reflexão sobre o contexto de discussões que circundam a temática da geodiversidade na Amazônia legal brasileira. Para alcançar o objetivo proposto, os procedimentos metodológicos constaram de: I levantamento e análise do referencial teóricometodológico e documental voltados a temática pesquisada; II - levantamento e análise das propostas de criação de geoparques para os estados da Amazônia Legal; III - levantamento e análise dos registros de geossítios e sítios da geodiversidade existentes nas plataformas Comissão Brasileira de Sítios Geológicos (SIGEP) e Cadastro de Sítios Geológicos (GEOSSIT); IV - levantamento de projetos de pesquisa, ensino e extensão voltados às temáticas da geodiversidade, geoconservação, Patrimônio Natural do meio abiótico, geoturismo e geoparque, na Amazônia; e V - tabulação das informações e representação em forma de mapas, tabelas, quadros, fotos e gráficos. Os resultados apontam que a Amazônia encontra-se em fase de amadurecimento conceitual e operacional, com barreiras no que diz respeito a infraestrutura e acesso a muitas áreas e ao fomento a atividades de pesquisa.
\end{abstract}

Palavras-chave: Amazônia. Geoturismo. Geoparques.

\section{PERSPECTIVES ON THE VALUATION OF GEODIVERSITY AND GEOCONSERVATION IN THE AMAZON}

\begin{abstract}
The discussions on the valorization of geodiversity have been gaining prominence in the Brazilian scenario and, more recently, in the Amazon. Thus, this article analyzes some initiatives that allow reflection on the development context that involves the theme of geodiversity in the Brazilian legal Amazon. In order to achieve the proposed objective, the methodological procedures consisted of:I - survey and analysis of the theoretical-methodological and documentary framework aimed at the researched theme; II - survey and analysis of the proposals for the creation of geoparks for the states of the Legal Amazon; III - survey and analysis of geosite records and geodiversity sites on the Brazilian Commission of Geological and Paleobiological Sites (SIGEP) and Geological Sites Registry (GEOSSIT) platforms; IV - survey of research, teaching and extension projects focused on the themes of geodiversity, geoconservation, Natural Heritage of the abiotic environment, geotourism and geopark, in the Amazon; and V tabulation of information and representation in the form of maps, tables, charts, photos and graphs. The results show that the Amazon is in the conceptual and operational maturation
\end{abstract}


stage, with barriers in terms of infrastructure and access to many areas and the promotion of research activities.

Key-words: Amazon. Geotourism. Geoparks.

\section{INTRODUÇÃo}

Em contraste com o nível de proteção alcançado pelo meio biótico por meio do Sistema Nacional de Unidades de Conservação, Lei do SNUC (2000), o meio abiótico carece de iniciativas voltadas à segregação de espaços territoriais na Amazônia.

Nesse contexto, o conhecimento sobre a geodiversidade pode ser a principal ferramenta a auxiliar na difusão das ideias de conservação do meio abiótico. Esse conhecimento pode ser proporcionado a partir das atividades como o turismo pautado na valorização do meio abiótico, mas também por meio de práticas educativas, nos diversos níveis de ensino, e que visam a popularização das informações sobre a geodiversidade de um determinado local.

A evolução do conceito de geodiversidade foi sistematizada por Gray (2004), que nesta obra intitulada "Geodiversity: valuing and conserving abiotic nature", apresenta o processo histórico de conservação geológica e geomorfológica. Segundo este autor, algumas práticas predatórias ao Patrimônio Natural do meio abiótico em países como a Escócia, nas primeiras duas décadas do século XIX, impulsionaram a necessidade de adoção de medidas legais de proteção (GRAY, 2004). Essa iniciativa foi seguida por vários países na Europa, Ásia, Américas, e a conceituação do termo geodiversidade passa, então, a ter ampla discussão por parte de pesquisadores envolvidos com as pesquisas nessa temática.

É importante informar que, ainda segundo Gray (2004), o conceito de geodiversidade nasceu no século XX, a partir da convenção de Malvern sobre conservação geológica e paisagística, realizada em 1993. No entanto, conforme afirma Lopes e Araújo (2011), foi somente a partir de 2001, com a publicação de um artigo de Mick Stanley, que a Royal Society for Nature Conservation, do reino Unido, começou a utilizar o termo, dando-o, assim, notoriedade.

Tem-se a década de 1990 como um marco para o avanço conceitual do tema entre geólogos e geomorfólogos no mundo, impulsionados, também, pela questão ambiental internacional marcada por conferências e reuniões, muito difundidas ao longo do século $X X$, conforme pode ser observado em Ribeiro (2001). Seria necessário incluir nas pautas sobre o meio ambiente, a geoconservação e temas associados.

Foi nesse contexto que, conceitualmente e metodologicamente, ageodiversidade e os temas correlatos passaram a ser minuciosamente discutidos e ganharam metodologias próprias de análise como foma de contribuir com as estratégias de geoconservação.

Nesse sentido Brilha (2005) define a geodiversidade como a variedade de ambientes geológicos, fenômenos e processos que dão origem a paisagem física, incluindo componentes como rochas, minerais, fósseis, solos e outros depósitos superficiais que são o suporte para a vida na Terra. Costa e Oliveira (2018), fazem uma leitura holística da geodiversidade, quando integra a este conceito uma concepção geográfica pautada na compreensão de que a litologia e a estrutura geológica atuam em conjunto com o clima, com a diversidade biológica, geomorfológica e pedológica. E, assim, dão suporte ao planejamento e gestão ambiental.

A geodiversidade é dotada de valores. Gray (2004), atribuiu os valores intrínseco, cultural, estético, econômico, funcional, científico e educativo à geodiversidade. Para Brilha (2005), o fato de a geodiversidade ter valores leva a necessidade de conservar. E é nesse envolto que várias metodologias de quantificação e avaliação da geodiversidade começam a ser aplicadas, com viés ao Patrimônio Geológico e/ou ao Patrimônio Geomorfológico, entre eles Brilha (2005); Pereira (2006); Pereira; Pereira; Alves (2007); Pereira (2010); Pereira e Brilha (2010); Garcia-Cortés e Urquí (2012); Monosso e Ondicol (2012); e Brilha (2016).

Todas as metodologias voltadas a quantificação da geodiversidade e construção de inventários tem finalidades voltadas a geoconservação (BRILHA et al., 2018). Através desses documentos metodológicos é possível localizar, popularizar, buscar alternativas sustentáveis de apropriação e conservar a geodiversidade. Por exemplo, a prática de geoturismo em uma área com aspectos geomorfológicos, geológicos, pedológicos, arqueológicos ou paleontológicos com notável beleza cênica, pode proporcionar que as comunidades que moram em locais próximos desenvolvam atividades em prol da sua sustentabilidade. E, ainda, promovam a valorização e promoção do

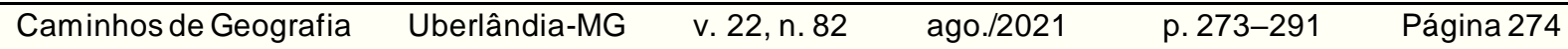


Patrimônio Natural. De acordo com Hose (2012), o geoturismo moderno conta com o aspectos dos 3Gs interrelacionados: geoconservação, geohistória e geo-interpretação.

A presença de geoparques já confirmam essa realidade, pois para a sua existência é necessário, acima de tudo, a inclusão da comunidade. De acordo com Hose (2012), as relações entre pessoas e geologia, através do geoparque, possui o potencial de desenvolvimento econômico. Sendo que, idealmente, o interesse geológico associado a algum interesse arqueológico, cultural, histórico ou ecológico, dentro das geoparques, necessita de uma provisão educacional.

O papel das instituições de ensino e de pesquisa são considerados fundamentais nesse processo de promoção da geodiversidade. É a partir das universidades que os projetos voltados ao ensino, a pesquisa e a extensão podem dar esse suporte a valorização do meio abiótico. Primeiramente, através do uso do potencial didático da geodiversidade para sensibilizar a comunidade dos variados níveis acadêmicos e as comunidades mais distantes, por meio do conhecimento das paisagens que os cerca, como pode ser observado a partir das iniciativas de Pereira; Rios; Garcia (2016); Santos e Jacobi (2017); Silva e Aquino (2018); Saldanha et al. (2019); e Meira et al. (2020). E, posteriormente, é possível construir formas que viabilizem o aproveitamento, pela comunidade, do suporte que o meio físico oferece para o desenvolvimento de atividades diversas, de forma sustentável, conforme observou-se em Costa e Oliveira (2018); Jorge (2018); e Moreira e Vale (2018).

E, também, destaca-se a relevância de iniciativas em escala global, como a atuação do programa Geoparques Globais da Unesco - Organização das Nações Unidas para Educação, Ciência e Cultura - , e, no caso do Brasil, a iniciativa nacional de criação e desenvolvimento do programa da Comissão Brasileira de Sítios Geológicos e Paleobiológicos (SIGEP), e do Cadastro de Sítios Geológicos (GEOSSIT), ambos ligados ao Serviço Geológico do Brasil (SGB/CPRM).

Para os estados da Amazônia, além das iniciativas antes mencionadas em nível institucional, as contribuições através dos projetos e dos trabalhos acadêmicos publicados têm alcançado proporções razoáveis com uma perspectiva favorável ao crescimento da produção sobre a temática da geodiversidade. Além de todos os nove estados da Amazônia Legal possuírem os seus levantamentos da geodiversidade elaborados pelo SGB/CPRM, em diferentes períodos, algumas produções acadêmicas em forma de artigos científicos, teses e trabalhos completos em eventos podem ser identificados.

Conforme as pesquisas em bases de dados on-line, observou-se o crescimento da literatura acadêmica publicada sobre a temática da geodiversidade e temas correlatos que abrangem os estados da Amazônia, a partir do final da década de 2010. Entre os trabalhos pesquisados, destacaram-se as contribuições com foco para o geoturismo, como observado em Figueiredo e Gorayeb (2009), que caracterizaram a geomorfologia e a geologia do Parque Estadual Serra dos Martírios-Andorinhas/PA, como contribuição ao potencial geoturístico na região sudeste do Estado; Palhares e Guerra (2016), que direcionaram a identificação do potencial geoturístico no município de Oiapoque, Amapá, como forma de viabilizar o desenvolvimento econômico; Andrade, Andrade e Carneiro (2017), que apresentaram um estudo de caso para a cidade de Santarém (PA), localizada na mesorregião do Baixo Amazonas, onde correlacionam a sua área urbana com a dinâmica geomorfológica dos rios Amazonas e Tapajós; Espirito Santo et al. (2018), com foco para a quantificação da geodiversidade no médio curso do rio Araguari, no município de Ferreira Gomes/AP, e a importância dessa metodologia para analisar o potencial geoturístico em geomorfossítios; e Falcão; Silva; Souza (2019), que trabalharam com a avaliação do potencial da geodiversidade do município de Uiramutã/RR, para o levantamento da viabilidade para o geoturismo.

Outros trabalhos, com outras perspectivas foram encontrados, como Silva e Rodrigues (2010), Silva (2012) e Silva et al. (2013), que analisaram a geodiversidade a partir da categoria geomorfologiafluvial, todos para a bacia hidrog ráfica do rio Xingu, PA. É importante reforçar a abrangência que os elementos fluviais têm quando se trata de Amazônia, dada a diversidade de sua rede de drenagem, diferentes especialidades, padrões, usos e etc.; Ferreira (2014), que a partir dos aspectos geomorfológicos ligados a dissecação do relevo, declividade do terreno, uso e cobertura vegetal, solos e precipitação pluviométrica, produziu uma carta de fragilidade potencial da área do Parques Estadual Serra Ricardo Franco (MT); e Espirito Santo (2018), com foco para a análise de risco e degradação dos solos a partir da quantificação do potencial erosivo em áreas de acesso a geomorfossítios, com viés de contribuir com a metodologia de quantificação da geodiversidade em trechos do médio curso da bacia hidrográfica do rio Araguari, Ap. 
É a partir desse cenário que o presente artigo objetiva analisar algumas iniciativas que permitem a reflexão sobre o contexto de discussões que circundam a temática da geodiversidade na Amazônia legal brasileira, como os cadastros de sítios e geossítios nos sistemas SIGEP e GEOSSIT, as propostas de geoparques para os estados amazônicos e os projetos de pesquisa, ensino e/ou extensão, em execução. E assim, refletir sobre as perspectivas futuras de valorização do patrimônio natural e da geoconservação para esta região.

\section{METODOLOGIA}

\section{Área de estudo}

O recorte espacial para o presente estudo é a Amazônia Legal, formada pelos estados: Acre, Amazonas, Amapá, Pará, Rondônia, Roraima, Tocantins, Oeste do Maranhão e o Mato Grosso (figura 1). O conceito de Amazônia Legal considerado está de acordo com a Lei n. 5173/1966 e a Lei Complementar n. 31/1977, que estabelecem as ações voltadas ao planejamento da Amazônia e regulamentam o seu Plano de Valorização Econômica.

Figura 1 - Mapa da área de estudo que inclui os estados da Amazônia Legal, segundo a Lei n. 5173/1966 e a Lei Complementarn. 31/1977.

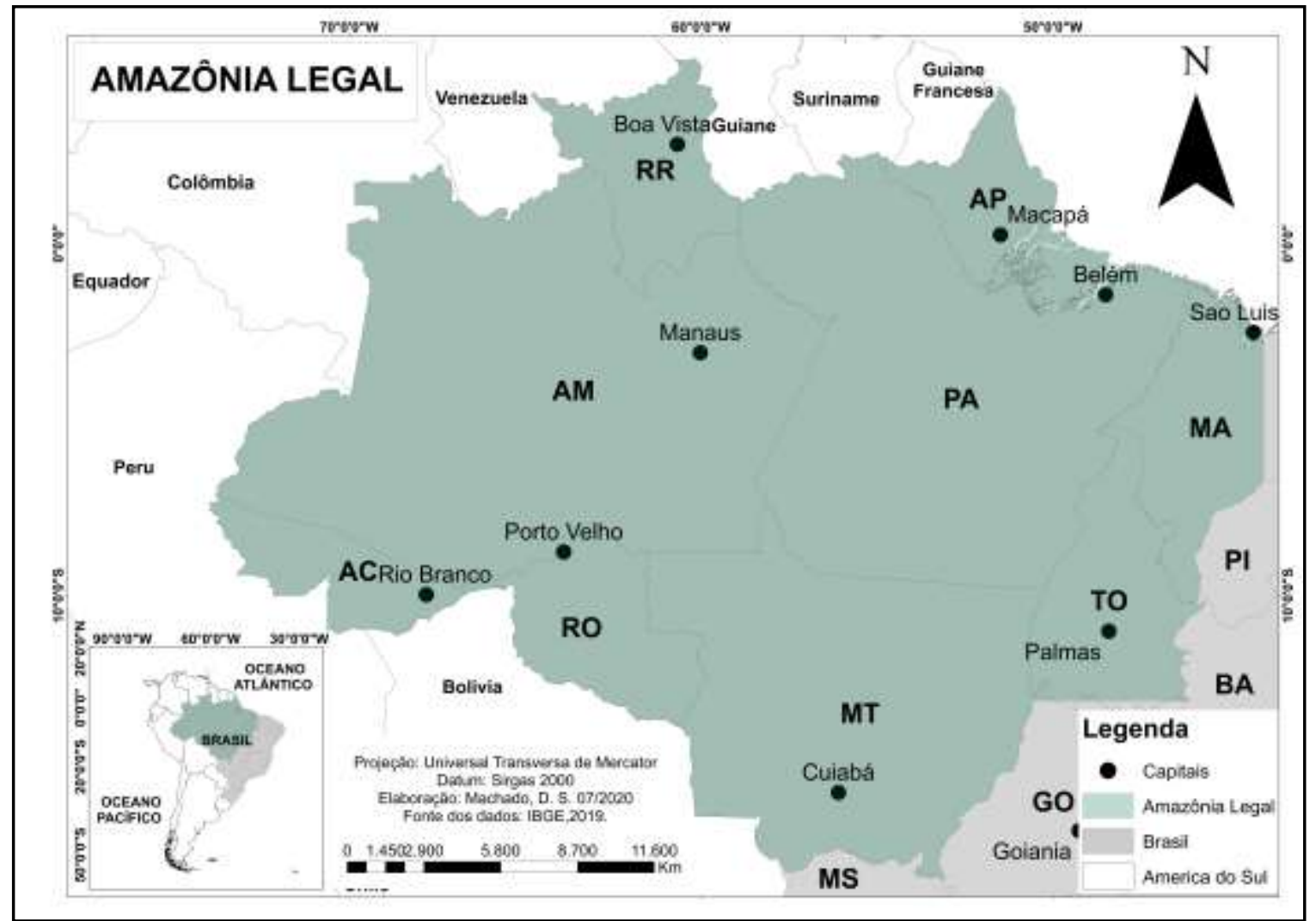

Fonte - Elaborado pelas autoras, (2020).

\section{Procedimentos metodológicos}

Os procedimentos metodológicos adotados constaram das seguintes etapas:

I - Levantamento e análise do referencial teórico, metodológico e documental. O referencial teórico e metodológico proporcionou clareza e compreensão dos principais temas abordados no presente estudo, são eles: a geodiversidade, a geoconservação, o Patrimônio Natural do meio abiótico; o

$\begin{array}{lllll}\text { Caminhos de Geografia } & \text { Uberlândia-MG } & \text { v. 22, n. } 82 & \text { ago./2021 } & \text { p. 273-291 }\end{array}$ Página 276


geoturismo e o geoparque. O suporte metodológico deste referencial permitiu analisar e correlacionar os estudos desenvolvidos em escala nacional e global, para fins de auxiliar nas reflexões feitas para a Amazônia;

II - Levantamento e análise das propostas de criação de Geoparque para os estados da Amazônia Legal. Este levantamento foi importante pois permitiu espacializar as propostas existentes por estado e município, analisar o atual cenário através da identificação do status da proposta e lançar uma reflexão sobre o amadurecimento conceitual, conjuntural e comparativo das mesmas;

III - Levantamento do registros de sítios catalogados nas plataformas: Comissão Brasileira de Sítios Geológicos e Paleobiológicos (SIGEP) e Cadastro de Sítios Geológicos (GEOSSIT), ambos vinculados ao SGB/CPRM. Os levantamentos feitos em ambas as plataformas, foram no sentido de enumerar os sítios, geossítios e sítios da geodiversidade dos estados amazônicos que encontram-se registrados nessas bases. A existência de registros indica iniciativas de valorização da geodiversidade e pode ser um banco de dados para que ações mais ef etivas possam ser construídas, no sentido de construção de políticas públicas voltadas a geoconservação, a educação e desenvolvimento local sustentável;

IV - Levantamento de projetos de pesquisa, ensino e extensão voltados às temáticas da geodiversidade, geoconservação, Patrimônio Natural do meio abiótico, geoturismo e geoparque, na Amazônia. Este levantamento foi feito, primeiramente, a partir das publicações científicas existentes para a área. Posteriormente, pesquisou-se nos currículos lattes de todos os autores dos trabalhos identificados, quais os projetos, finalizados ou em execução, de pesquisa, ensino e extensão desenvolvidos sobre as temáticas pesquisadas neste artigo. Fez-se uma tentativa de levantamento em sites de universidades dos estados Amazônicos, especialmente em sites dos cursos de graduação e pós-graduação em geografia e geologia, visando identificar projetos de pesquisa e extensão que atuam com temática da geodiversidade. No entanto, muita informação não se encontra disponível, o que leva a sugerir a possível existência de um potencial maior de trabalhos existentes; e,

V - Tabulação das informações e representação em forma de mapas, tabelas, quadros, fotos e gráficos.

\section{RESULTADOS E DISCUSSÃO}

\section{Propostas de geoparques para a Amazônia}

Os geoparques são territórios geográficos com paisagens geológicas, geomorfológicas, mineralógicas, paleontológicas, arqueológicas, hidrogeológicas, pedológicas, dentre outras particularidades, que em nível internacional apresentam ampla necessidade de conservação, dados os valores cultural, econômico, estético, educativo e científico que essas paisagens apresentam. Além de que registram importantes aspectos do processo de evolução da Terra, aspectos esses que foram construídos ao longo do tempo de formação do planeta, sob condições diversas tanto endogenéticas quanto exogenéticas, além da contribuição do homem, em algum momento desse processo evolutivo.

O início do século XXI trouxe novas formas de pensar a conservação da natureza em nível global, e os Geoparques Globais da Unesco surgiram como um exemplo dessa nova conjuntura, cuja base foi herdada da última década do século XX, quando se começou a inserir novas discussões que incluíssem, agora, a valorização e conservação do patrimônio natural. Essas novas abordagens estão pautadas, por exemplo, nos debates que surgiam ao entorno do conceito de geodiversidade na década supracitada. Mansur (2018), apresenta uma vasta bibliografia com a evolução dos conceitos de geodiversidade, bem como os fenômenos e processos associados em um período que percorre a última década do século XX e as duas primeiras do século XXI.

Entende-se que essa nova abordagem chega de forma a complementar os modelos vigentes de preservação do meio biótico, ou seja, a biodiversidade. As interrelações conceituais entre a geodiversidade e a biodiversidade foram discutidas por Brilha et al. (2018). Estes autores definiram uma rede de ligações conceituais que partem da geodiversidade e interligam todos os outros termos usuais dessa área do conhecimento, culminado em um manejo sustentável dos georecursos.

Então, com a iniciativa da Unesco surge uma forma holística de pensar a conservação, pautada não apenas na biodiversidade e na geodiversidade, mas também no importante papel desempenhado pela educação e pelo suporte ao desenvolvimento local sustentável dos espaços com relevância para a

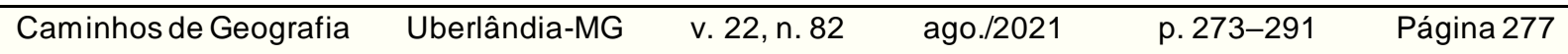


proteção. É importante considerar o fato de que a partir do ano de 2006 o SGB/CPRM, através do Projeto Geoparques, começou a induzir a criação de novos geoparques no Brasil.

Até o presente ano, de 2020, existe no Brasil um Geoparque (Geopark Araripe) vinculado ao Programa Geoparque Global da Unesco, e está localizado na porção sul do estado do Ceará, região Nordeste. Em 2020, os candidatos a geoparques "Caminhos cânions do Sul" (RS/SC) e "Geoparque Seridó" (RN), elevaram-se a categoria de geoparques aspirantes e entrarão no processo oficial de avaliação para que recebam o selo de Unesco. Incluindo os dois geoparques aspirantes, existem hoje no Brasil 37 propostas de criação de geoparques elaboradas pelo SBG/CPRM (figura 2).

Figura 2 - Proposta de criação de geoparques no Brasil.

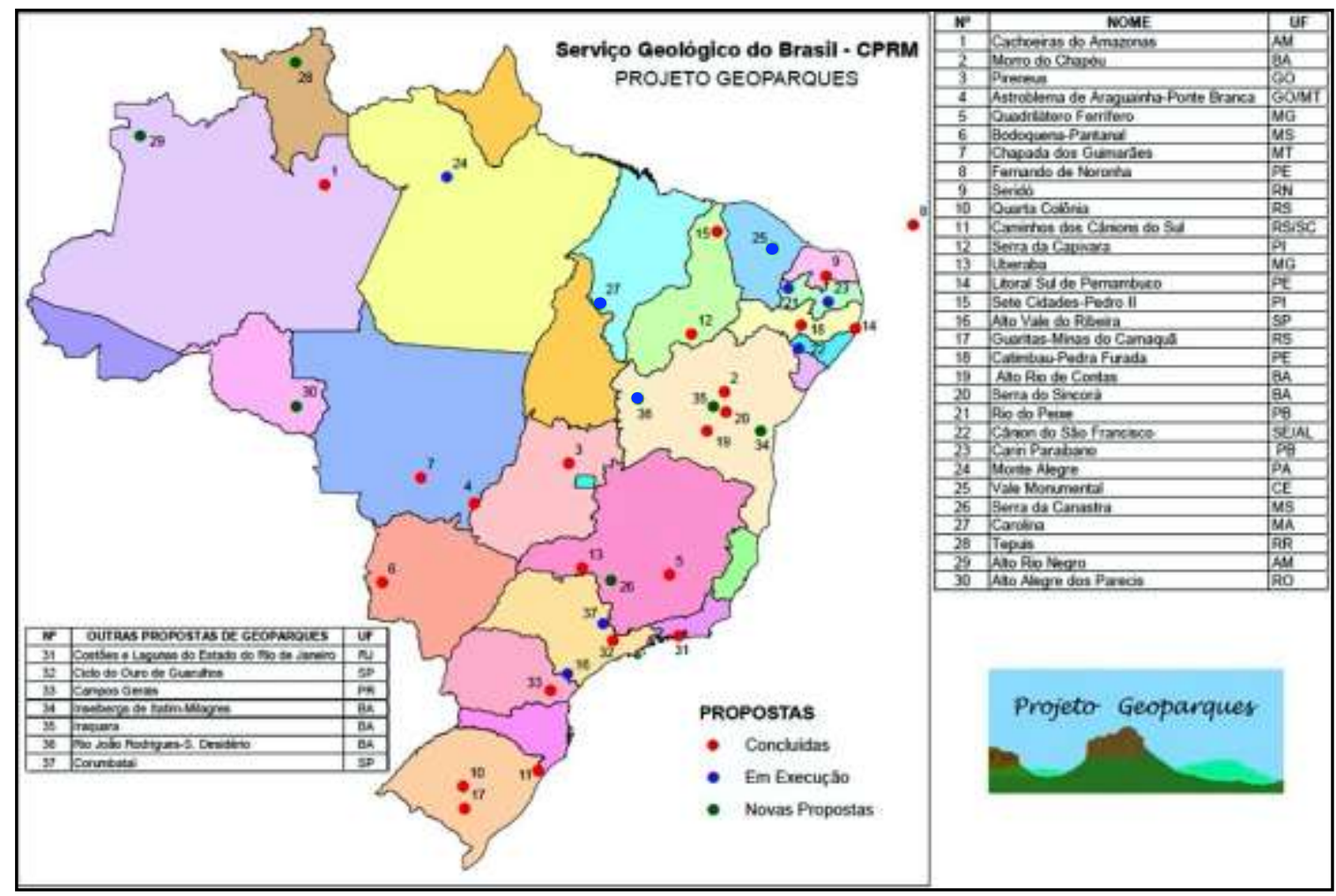

Fonte - Atualizado de MEIRA e SILVA, 2018.

* Entre os anos de 2018 e 2020, três propostas de geoparque (Vale Monumental, Carolina e Rio João Rodrigues_S. Desidério) elevaram-se da condição de novas propostas para em execução, com suas publicações disponibilizadas através do Repositório Institucional de Geociências, disponível em: http://rigeo.cprm.gov.br/jspui/handle/doc/13694.

Desse quantitativo de propostas, a maior parte encontra-se na região Nordeste (17), seguida do Sudeste (07), Norte (05), Sul (04) e Centro-oeste (04). A literatura mostra que regiões Nordeste e Sudeste apresentam um número elevado de estudos voltados a inventários, quantificações, diagnósticos, roteiros para o geoturismo e estão a frente com seus projetos de criação de geoparques no Brasil. Da mesma forma, as regiões Sul e Centro-Oeste trilham o mesmo caminho. Além de existir infra-estrutura compatível com atividades que visam a valorização do patrimônio natural através da divulgação de desenvolvimento local sustentável.

No caso da região Norte, embora existam cinco propostas de criação de geoparques (3 novas propostas, 1 concluída e 1 em execução), os inventários da geodiversidade, as pesquisas sobre esta temática, a popularização das geociências, encontram-se, ainda em fase inicial, em comparação com o que se tem produzido na região Nordeste, por exemplo.

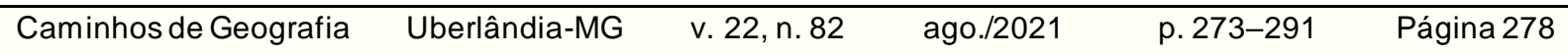


Quando se analisa o recorte da Amazônia Legal, que é a escala espacial trabalhada no presente artigo, tem-se um total de sete propostas de criação de geoparques para a região (quadro 1). Região esta que possui a maior bacia hidrográfica do planeta, o maior recorte de floresta densa do Brasil, uma diversidade de domínios geológicos e geomorfológicos sob atuação de diferentes tipos e subtipos climáticos, além da presença de uma pluralidade de atores sociais e conflitos diversos pelo uso e apropriação da diversidade de recursos.

Quadro 1 - Propostas de geoparques para os estados da Amazônia.

\begin{tabular}{|c|c|c|c|}
\hline Estado & Geoparque & Situação/fase & Municípios \\
\hline \multirow{2}{*}{ Amazonas } & Cachoeiras do Amazonas & $\begin{array}{l}\text { Proposta concluída em } \\
2012\end{array}$ & Presidente Figueiredo \\
\hline & Alto rio Negro & Nova proposta & Sem informações \\
\hline Maranhão & Vale das águas & $\begin{array}{l}\text { Nova proposta concluída } \\
\text { em } 2019\end{array}$ & $\begin{array}{l}\text { Carolina, Estreito e } \\
\text { Riachão }\end{array}$ \\
\hline Mato Grosso & Chapada dos Guimarães & $\begin{array}{l}\text { Proposta concluída em } \\
2012\end{array}$ & $\begin{array}{c}\text { Chapada dos Guima- } \\
\text { rães, Campo Verde e } \\
\text { Santo Antônio do Lever- } \\
\text { ger }\end{array}$ \\
\hline Pará & Monte Alegre & Proposta em execução & Sem informações \\
\hline Rondônia & Alto Alegre dos Parecis & Nova proposta & Sem informações \\
\hline Roraima & Tepuis & Nova proposta & Sem informações \\
\hline
\end{tabular}

Fonte - Elaboração das autoras, baseado em CPRM, 2020.

Entre as seis propostas espacializadas pelo SGB/CPRM, para apenas três existem documentos em forma de inventário e proposta de criação de geoparque, são elas: Cachoeiras do Amazonas, que contempla o município de Presidente Figueiredo, no estado do Amazonas, e foi concluída em 2012 com oito geossítios inventariados por Luzardo (2012); Vale das Águas, que envolve os municípios de Carolina, Estreito e Riachão, no estado do Maranhão, e foi concluída em 2019 com o inventário de 21 geossítios feito por Barros; Filho; Freitas (2019); e Chapada dos Guimarães, no estado do Mato Grosso, com a proposta concluída por Junior, Moraes e Paula (2012), com o inventário de 16 geossítios. As demais propostas encontram-se em fase de novas propostas e em execução.

A proposta Cachoeiras do Amazonas apresenta a caracterização fisiográfica da área que compreende o município que abarcará o geoparque, bem como ilustra e detalha as características que dão excepcionalidade a cada geossítio, como a presença de cachoeiras, grutas, perfis lateríticos, paleodunas, e etc. Sendo que a proposta é incisiva ao demostrar a importância da conservação quando deixa claro os diferentes tempos de formação de cada geossítio. Também é possível visualizar como é feito o acesso a cada área inventariada. De acordo com Reis; Faria; Fraxe (2020) a área dessa proposta conta com uma sobreposição de outros territórios institucionais, como assentamentos rurais e unidades de conservação. Os autores fazem uma sugestão de um plano de ação com sugestões mínimas para implementação do geoturismo dentro da proposta de geoparque.

Com relação a proposta Vale das Águas, acredita-se que porser de elaboração mais recente apresenta uma base conceitual bem evoluída, quando, por exemplo, alcança objetivos além da caracterização e inventário, e enquadra o local em geossítio ou sítio da geodiversidade. E o embasamento para a classificação é a atribuição do valor científico, além dos turístico e de risco de degradação. Muniz e

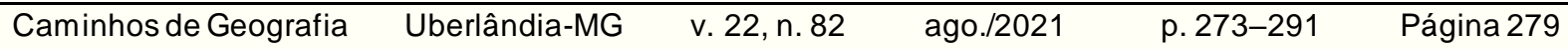


Castro (2018) apontam que o turismo acontece de forma crescente na região de proposição deste geoparque. Os autores analisam que a expansão da atividade ocorre sem levar em consideração as fragilidades do bioma local e concluem com a indicação de ausência de estudos de educação para preservação ambiental.

A proposta Chapada dos Guimarães mostra um contexto fisiográfico que reforça o potencial turístico da área que abrangerá o geoparque, dados os interesses geológico-geomorfológico, paleontológico e espeleológico, além do potencial relacionado ao patrimônio histórico e pré-histórico que existe na área. Kuhn e Tobias (2017), quando propõem o roteiro geoturístico como instrumento de ensino, reconhecem a diversidade de rochas, relevos, solos e processos intempéries relacionados a evolução da paisagem nesses substratos. Marcelino; Alvarenga; Mathias (2019), reforçam o valor educativo de geossítio componente da Chapada dos Guimarães e chamam a atenção para a importância de maiores estudos e da melhora da infra-estrutura de acesso, por conta de processos erosivos que inviabilizam em alguns momentos a chegada até o local.

Embora a região Amazônica tenha ef etivamente poucas propostas, o cenário leva a refletir o esforço de algumas instituições em construir seus inventários e propor esse novo instrumento de conservação da natureza que pode ser uma alternativa à geoconservação a partir do tripé: conservação da geodiversidade, geoeducação e subsídio ao desenvolvimento local. Por outro lado, alguns empecilhos merecem ser destacados para a realidade da região amazônica, como, por exemplo: a questão da precariedade da infra-estrutura de acesso aos locais potenciais; a falta de subsídio econômico através das agências de fomento; a própria necessidade de amadurecimento conceitual sobre a nova temática; a fraca presença de disciplinas voltadas a temática em cursos de graduação e pós-graduação em geografia e em geologia das universidades; e não menos importante, a pouca presença da temática nos livros didáticos e nas aulas nos ensinos fundamental e médio.

Defende-se que a base para uma perspectiva positiva das ações de geoconservação a partir da criação de geoparques está na educação, na valorização da cultura, do patrimônio, da identidade e da ciência, bem como no desenvolvimento socioeconômico das comunidades.

\section{Registros de sítios a partir da Comissão Brasileira de Sítios Geológicos e Paleobiológicos (SIGEP) e do Cadastro de Sítios Geológicos (GEOSSIT)}

As ações voltadas a preservação da história da Terra visando práticas de conservação da geodiversidade, podem ocorrer, conforme visto anteriormente, por meio das pesquisas, projetos em educação e estratégias territoriais como a criação de geoparques.

Outras iniciativas, anteriores e/ou complementares, como o cadastro e registro de sítios de categorias diversas em bancos de dados e/ou aplicativos oficiais, como é o caso da SIGEP e do GEOSSIT, são importantes indicadores para avaliar o nível de reconhecimento e divulgação da geodiversidade existente em diversos estados do Brasil. Uma vez que, inclusive, tratam-se de inventários que dada a relevância e importância de proteção para guardar a história evolutiva da Terra, podem gerar propostas de criação de geoparques.

Até fevereiro de 2020, a SIGEP (2020b) dispunha de três volumes de livros publicados com os inventários dos Sítios Geológicos e Paleontológicos do Brasil. Somando as três obras, o total de sítios de categorias diversas é de 114, das quais cinco estão localizados na Amazônia.

Os sítios da Amazônia cadastrados na SIGEP enquadram-se nas categorias paleontológico (2), espeleológico (1) e geomorfológico (2) (quadro 2). Além desses, a CPRM disponibiliza uma lista com propostas de geossítios aprovadas pela SIGEP (2020c), todavia não publicadas, entre as quais estão

$\begin{array}{lllll}\text { Caminhos de Geografia } & \text { Uberlândia-MG } & \text { v. 22, n. } 82 & \text { ago./2021 } & \text { p. 273-291 Página } 280\end{array}$



Jucilene Amorim Costa

Perspectivas sobre a valorização da geodiversidade e a geoconservação na Amazônia Walmira Ferreira Lopes

quatro sítios na Amazônia que encontram-se enquadrados nas categorias geomorfológico e paleoambiental (quadro 2).

Quadro 2 - Identificação de sítios para a área de estudo localizados no SIGEP.

\begin{tabular}{|c|c|c|c|}
\hline Sítios & Categoria & Estado & Volume no SIGEP/Ano \\
\hline Ilha de Fortaleza & Paleontológico & Pará & $1 / 2002$ \\
\hline $\begin{array}{l}\text { Caverna Aroe Jari, } \\
\text { Chapada dos } \\
\text { Guimarães }\end{array}$ & Espeleológico & Mato Grosso & $1 / 2002$ \\
\hline Monte Roraima & Geomorfológico & Roraima & II/2009 \\
\hline Pedra Pintada & Geomorfológico & Roraima & II/2009 \\
\hline Mina B-17 & Paleontológico & Pará & II/2009 \\
\hline $\begin{array}{l}\text { Ponta das lajes e o } \\
\text { encontro das águas }\end{array}$ & Sedimentológico & Amazonas & III/2013 \\
\hline Pico da Neblina* & Geomorfológico & Amazonas & Sítio não publicado \\
\hline $\begin{array}{c}\text { Dunas do Araça, Bar- } \\
\text { celos }^{\star}\end{array}$ & Paleoambiental & Amazonas & Sítio não publicado \\
\hline $\begin{array}{l}\text { Chapada dos } \\
\text { Guimarães* }\end{array}$ & Geomorfológico & Mato Grosso & Sítio não publicado \\
\hline $\begin{array}{l}\text { Baías do Pantanal, fron- } \\
\text { teira Brasil-Bolívia* }\end{array}$ & Geomorfológico & Mato Grosso & Sítio não publicado \\
\hline
\end{tabular}

Fonte - Elaboração das autoras, com dados de SIGEP, 2020. *Geossítios na Amazônia que foram aprovados pela SIGEP, porém até a publicação do presente artigo não foram publicados.

Cabe informar que, além dos sítios publicados e não publicados, a SIGEP dispõe de uma lista de sugestões preliminares de sítios que foram encaminhados por geocientistas com interesse no reconhecimentos de tais locais. No entanto, por motivos diversos, muitas dessas propostas ou foram canceladas ou encontram-se em fase de reformulação, como é o exemplo dos sítios Pedra Furada e Campos de Dunas, ambos com interesses geomorfológico e sedimentológico, e estão localizados no Jalapão - TO, Amazônia.

Através dos registros do GEOSSIT, identificou-se que existem registrados e disponíveis no Brasil 277 sítios, que estão em diferentes status de reconhecimento pela plataforma, são eles em análise, revisado ou homologados. É relevante informar que existem ainda um número de sítios que foram cadastrados, no entanto não foram publicados, por isso não estão disponíveis para consulta. Além de informações relativas a identificação, ao contexto, a caracterização geológica, as feições do relevo, ao interesse e ao enquadramento legal, todos os geossítios cadastrados no GEOSSIT foram quantificados quanto aos

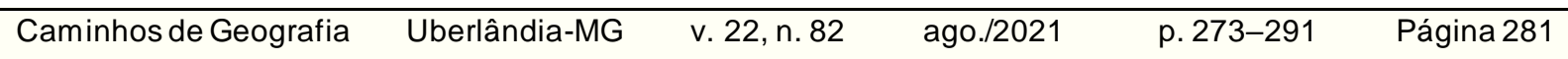



Jucilene Amorim Costa

Perspectivas sobre a valorização da geodiversidade e a geoconservação na Amazônia Walmira Ferreira Lopes

valores: científico, risco de degradação e potencial uso educativo e turístico. Isso proporciona a análise da relevância do geossítio, se é regional/local, nacional, internacional ou se não apresenta uma classificação aparente.

A escala de relevância é um item muito importante na definição das estratégias de geoconservação, e tal tem uma ligação estreita com a produção científica, como pode-se observar na metodologia de quantificação da geodiversidade utilizada por Pereira (2006). Nesta metodologia existe um indicador de valor científico, que diz que uma quantidade de publicações internacionais maior sobre uma dada área, eleva o seu valor. Logo, geossítios com alta valorização e divulgação, além de sua excepcionalidade e raridade, podem ser considerados de relevância internacional.

Com relação aos sítios da geodiversidade e geossítios dos estados amazônicos, cadastrados no GEOSSIT, identificou-se que existem 11, oito localizados no estado do Amazonas, um localizado no estado de Roraima, um localizado no estado do Tocantins e um localizado no estado do Maranhão (quadro 3). E, é possível analisar a quantificação e valores da geodiversidade, feitos a partir das metodologias de Brilha (2005), Garcia-Cortés e Urquí (2009) e Brilha (2016) (figura 3). A partir dessas metodologias definiu-se que a relevância é nacional ou internacional quando o valor científico do geossítio correspondem a igual ou maior que 200 ou igual ou maior que 300 , respectivamente. $O$ potencial de uso educativo e turístico deve apresentar valor igual ou superior a 200 (SGB/CPRM, 2020a).

Quadro 3 - Geossítios e sítios da geodiversidade da Amazônia Legal e sua relevância.

\begin{tabular}{|c|c|c|}
\hline GEOSSÍTIO & Estado & Relevância \\
\hline 1 - Cachoeira da Pedra Furada & Amazonas & Nacional \\
\hline 2 - Cachoeira da Porteira & Amazonas & Nacional \\
\hline 3 - Folhelhos carbonosos da Formação Manacapuru & Amazonas & Nacional \\
\hline 4 - Caverna refúgio do Maroaga e Gruta da Judéia & Amazonas & Internacional \\
\hline 5 - Cachoeira da Iracema & Amazonas & Local \\
\hline 6 - Serra Abonari & Amazonas & Nacional \\
\hline 7 - Formação Prosperança & Amazonas & Local \\
\hline 8 - Platô Laterífico & Amazonas & Local \\
\hline 9 - Monte Roraima & Roraima & Internacional \\
\hline 10 - Floresta Petrificada do Tocantins & Tocantins & Internacional \\
\hline 11 - Cabeça de Sapo & Maranhão & Nacional \\
\hline
\end{tabular}

Fonte - Elaboração das autoras, com dados de GEOSSIT, 2020.

$\begin{array}{lllll}\text { Caminhos de Geografia } & \text { Uberlândia-MG } & \text { v. 22, n. } 82 & \text { ago./2021 } & \text { p. 273-291 }\end{array}$ Página 282


Figura 3 - Quantificação de Geossítios e Sítios da Geodiversidade da Amazônia inventariados através do GESOSSIT/SGB/CPRM.

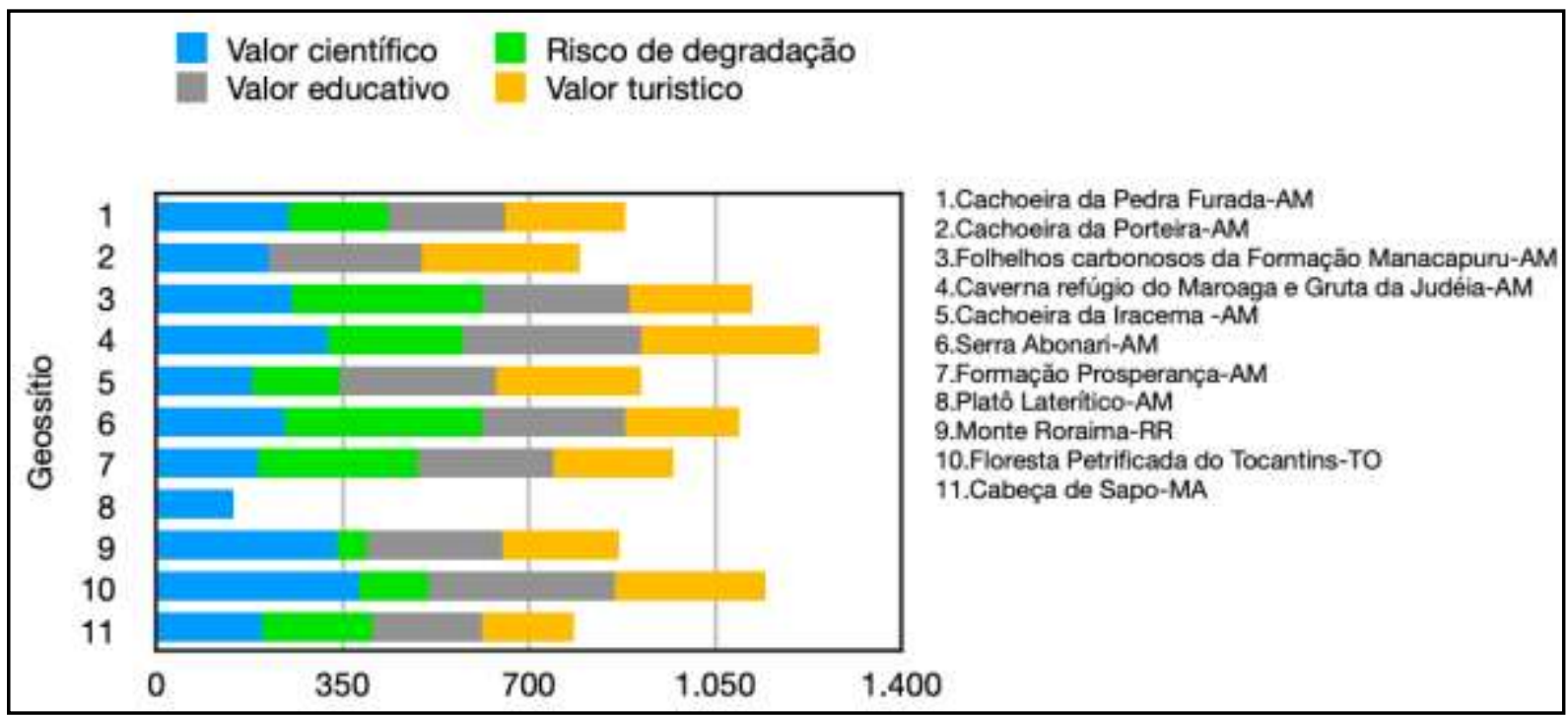

Fonte - Elaboração das autoras, a partir dos dados do GEOSSIT, 2020.

É possível fazer algumas reflexões relacionadas à já mencionada relação entre os valores científicos e a relevância dos geossítios perante as escolas internacional, nacional e local. Avalia-se que dez sítios geológicos inventariados têm valor educativo alto, o que significa que podem ilustrar importantes processos relacionados a evolução da Terra e que são acessíveis a estudantes e à comunidade em geral.

Apenas dois sítios geológicos apresentados foram quantificados abaixo do esperado com relação ao valor turístico. O primeiro foi o "Cabeça de Sapo", no estado do Maranhão, por ter apresentado baixo valor relacionado à ocorrência de elementos geológicos e pouca ocorrência de elementos da geodiversidade passiveis de observação. E o segundo foi o "Platô Laterífico", que recebeu a menor pontuação em seus valores educativo e turístico, e acredita-se que por apresentar status "em análise" possam ocorrer atualizações e inclusão de informações o que poderá elevar os valores que encontramse prejudicados na avaliação.

Os sítios geológicos "Cachoeira da Iracema", "Formação Prosperança"e "Platô Laterítico", todos no estado do Amazonas, apresentaram valor científico abaixo de 200, o que os atribui uma relevância local. Em geral, o não registro de conhecimento científico, a baixa possibilidade de visualização e interpretação de processos geológicos e a pouca divulgação em eventos, estão entre os principais indicadores de quantificação do valor científico que receberam um baixo peso no processo de quantificação, e por isso a "baixa" relevância.

De forma geral, avalia-se que através das duas formas de contribuição ao inventário da geodiversidade da Amazônia ainda é incipiente a quantidade de sítios e sítios da geodiversidade inventariados perante a dimensão e diversidade da região. Todavia, essas são importantes iniciativas que poderão ser o caminho para que outros inventários sejam elaborados e divulgados e estratégias de geoconservação sejam criadas para o Patrimônio Natural abiótico da Amazônia.

\section{O ensino, a pesquisa e a extensão a partir dos temas geodiversidade, geoconservação e geoturismo na Amazônia}

A universidade e os institutos de pesquisa se aproximam da comunidade e transmitem o conhecimento a partir de atividades de extensão. Com uso de uma linguagem didática, é possível que a população sensibilize e valorize o seu patrimônio natural, pois constrói uma relação de identidade e pertencimento. Quando isso é acompanhado de planos para o desenvolvimento local sustentável, as práticas da interpretação ambiental e valorização dos sítios podem ser melhor efetivadas, uma vez que as comunidades começam a fazer um aproveitamento sustentado dos recursos que a circunda. Logo,

$\begin{array}{lllll}\text { Caminhos de Geografia } & \text { Uberlândia-MG } & \text { v. 22, n. } 82 & \text { ago./2021 } & \text { p. 273-291 Página } 283\end{array}$


Celina Marques do Espirito Santo

Milena Marília Nogueira de Andrade Jucilene Amorim Costa

Perspectivas sobre a valorização da geodiversidade e a geoconservação na Amazônia

Danusa da Silveira Machado Walmira Ferreira Lopes

promoverá a sua geoconservação. Jorge (2018), exemplifica com clareza uma série de projetos que proporcionaram a educação ambiental e a divulgação das geociências, através do estreitamento entre as comunidades científica e local.

É nesse escopo que a pesquisa, a dinamização do conhecimento e o envolvimento de outras entidades públicas e privadas ganham uma maior importância, dada a possibilidade de auxiliar na construção desses planos. Entretanto, trata-se uma reflexão que não cabe nos limites do presente artigo e sim, cabe neste apenas apresentar um panorama do papel das instituições de ensino perante a temática abordada, no caso, para a realidade amazônica, conforme sistematizado no quadro 4.

Quadro 4 - Sistematização dos projetos a partir dos temas da geodiversidade, geoconservação e geoturismo na Amazônia.

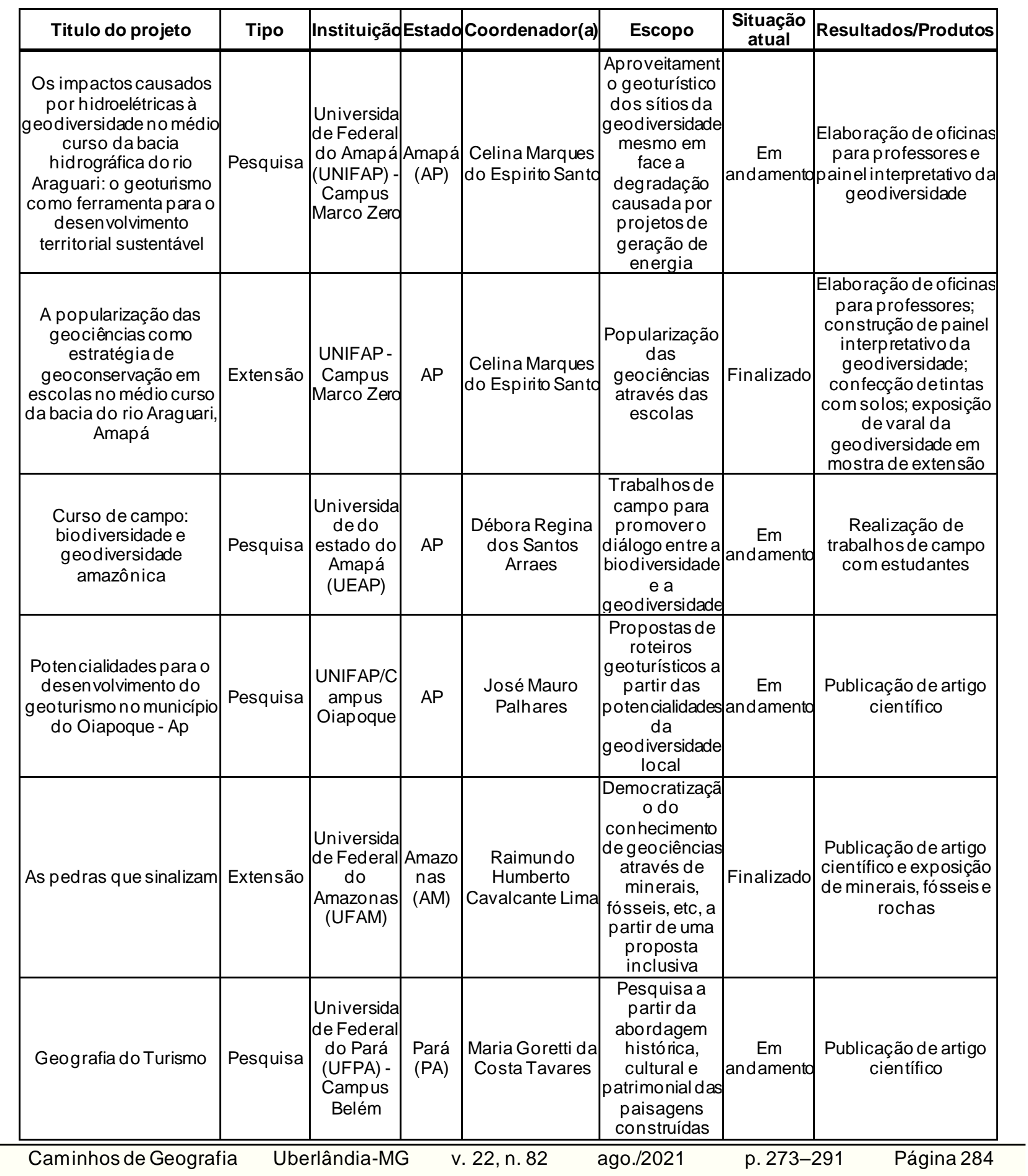


Perspectivas sobre a valorização da geodiversidade

Celina Marques do Espirito Santo

Milena Marília Nogueira de Andrade Jucilene Amorim Costa

e a geoconservação na Amazônia

Danusa da Silveira Machado Walmira Ferreira Lopes

\begin{tabular}{|c|c|c|c|c|c|c|c|}
\hline Titulo do projeto & Tipo & Instituiçãd & Estado & Coordenador(a) & Escopo & $\begin{array}{c}\text { Situação } \\
\text { atual }\end{array}$ & Resultados/Produtos \\
\hline $\begin{array}{l}\text { Roteiros Geo-turísticos } \\
\text { em Belém do Pará }\end{array}$ & Extensão & $\begin{array}{l}\text { UFPA- } \\
\text { Campus } \\
\text { Belém }\end{array}$ & PA & $\begin{array}{c}\text { Maria Goretti da } \\
\text { Costa Tavares }\end{array}$ & \begin{tabular}{|c|} 
Levar para a \\
comunidade a \\
abordagem \\
histórica, \\
cultural e \\
patrimonial das \\
paisagens \\
construídas \\
\end{tabular} & Em & $\begin{array}{c}\text { Aplicação de roteiros } \\
\text { geoturísticos temáticos } \\
\text { na área urbana de } \\
\text { Belém }\end{array}$ \\
\hline $\begin{array}{c}\text { Geodiversidade, } \\
\text { potencial geoturístico e } \\
\text { geoconservação dailha } \\
\text { de Mosqueiro, Belém-Pa }\end{array}$ & Pesquisa & $\begin{array}{c}\text { UFPA- } \\
\text { Campus } \\
\text { Ananindeu } \\
\text { a }\end{array}$ & PA & $\begin{array}{c}\text { Luciana Martins } \\
\text { Freire }\end{array}$ & \begin{tabular}{|c|} 
Pesquisa em \\
geoturismo \\
para promover \\
a \\
geoconservaçã \\
o \\
\end{tabular} & $\begin{array}{c}\text { Em } \\
\text { andamento }\end{array}$ & $\begin{array}{l}\text { Aplicação de roteiros } \\
\text { geoturísticos na ilha de } \\
\text { Mosqueiro, belém-Pa }\end{array}$ \\
\hline $\begin{array}{c}\text { Roteiro Geoturístico na } \\
\text { ilha de Mosqueiro, } \\
\text { Belém-Pa }\end{array}$ & Pesquisa & $\begin{array}{c}\text { UFPA- } \\
\text { Campus } \\
\text { Ananindeu } \\
\text { a }\end{array}$ & PA & \begin{tabular}{c|}
$\begin{array}{c}\text { Luciana Martins } \\
\text { Freire }\end{array}$ \\
\end{tabular} & \begin{tabular}{|} 
Realização dos \\
roteiros \\
geoturísticos a \\
partir do \\
patrimônio \\
geológico e \\
geomorfológico
\end{tabular} & \begin{tabular}{|c|} 
Em \\
andamento \\
\end{tabular} & $\begin{array}{l}\text { Aplicação de roteiros } \\
\text { geoturísticos na ilha de } \\
\text { Mosqueiro, belém-Pa }\end{array}$ \\
\hline $\begin{array}{l}\text { Roteiros Santarenos: Ge } \\
\text { ologia, História e Turismo }\end{array}$ & $\begin{array}{c}\text { Pesquisa e } \\
\text { extensão }\end{array}$ & $\begin{array}{c}\text { Universida } \\
\text { de Federal } \\
\text { do Oeste } \\
\text { do Pará } \\
\text { (UFOPA) }\end{array}$ & PA & $\begin{array}{c}\text { Deize de Souza } \\
\text { Carneiro }\end{array}$ & \begin{tabular}{|c|} 
Educação \\
patrimoniale \\
ambiental da \\
comunidade \\
acadêmica de \\
Santarém \\
\end{tabular} & Finalizado & \begin{tabular}{|c|} 
Realização de \\
excursões geológicas \\
pela área urbana da \\
cidadede Santarém
\end{tabular} \\
\hline $\begin{array}{c}\text { Patrimônio Histórico Ar- } \\
\text { quitetônico e Geológico: } \\
\text { Iniciativas de Divulgação } \\
\text { e Preservação através da } \\
\text { Educação }\end{array}$ & Extensão & UFOPA & PA & $\begin{array}{l}\text { Fernanda Souza } \\
\text { do Nascimento }\end{array}$ & $\mid \begin{array}{c}\text { Geoeducação } \\
\text { a partir das } \\
\text { perspectivas } \\
\text { histórica e } \\
\text { geológica local }\end{array}$ & Finalizado & \begin{tabular}{|c|} 
Realização de \\
excursões no centro da \\
cidadede Santarém \\
para apresentar \\
informações históricas \\
e o contexto g eológico \\
local \\
\end{tabular} \\
\hline $\begin{array}{c}\text { Estudo do patrimônio } \\
\text { geo mo rfológico no } \\
\text { entorno da sede do } \\
\text { município de Uiramutã - } \\
\text { RR } \\
\end{array}$ & Pesquisa & UFRR & $\mathrm{RR}$ & $\begin{array}{l}\text { Márcia Teixeira } \\
\text { Falcão }\end{array}$ & $\left|\begin{array}{c}\text { Geoturísmo a } \\
\text { partir do estudo } \\
\text { do patrimônio } \\
\text { geomorfológico }\end{array}\right|$ & Finalizado & $\begin{array}{l}\text { Publicação de artigo } \\
\text { científico }\end{array}$ \\
\hline
\end{tabular}

Fonte - Elaboração das autoras, a partir das pesquisas realizadas para o presente artigo, 2020.

No estado do Amapá pode-se registrar as contribuições com os estudos de geodiversidade, geoconservação e geoturismo, a partir dos projetos de pesquisa e extensão intitulados, respectivamente: "Os impactos causados por hidroelétricas à geodiversidade no médio curso da bacia hidrográfica do rio Araguari: o geoturismo como ferramenta para o desenvolvimento territorial sustentável"1 e "A popularização das geociências como estratégia de geoconservação em escolas no médio curso da bacia do rio Araguari, Amapá"2, coordenados pela professora Dra. Celina Marques do Espirito Santo, da Universidade Federal do Amapá (UNIFAP).

Considerando esses projetos o Patrimônio Natural do meio abiótico éo principal elemento considerado, onde as atividades realizadas constam de: inventariação, quantificação, análise de risco de degradação dos solos em áreas de acesso a geomorfossítios e sítios pedológicos e arqueológicos presentes na área, construção de roteiros geoturísticos, elaboração e aplicação de oficina para professores da rede pública e alunos do curso de licenciatura em geografia da UNIFAP, confecção de mapas e painel interpretativo (figura 4). Todas essas atividades foram realizadas com foco para a geodiversidade in situ e visaram a elaboração de propostas para a geoconservação através da popularização do conhecimento sobre tal. É importante citar que esses projetos foram precedidos da pesquisa de tese de doutorado, intitulada : "Geoconservação no estado do Amapá: uma contribuição metodológica do 'Valor de Conservação do Solo' para a avaliação da geodiversidade no médio curso do rio Araguari" (ESPIRITO SANTO, 2018).

${ }_{1}^{1}$ Projeto financiado pela Fundação de Apoio à Pesquisa do Estado do Amapá (FAPEAP);

2 Projeto desenvolvido com recursos da Pró-Reitoria de Extensão e Ações Comunitárias (PROEAC/UNIFAP);

$\begin{array}{lllll}\text { Caminhos de Geografia } & \text { Uberlândia-MG } & \text { v. 22, n. } 82 & \text { ago./2021 } & \text { p. 273-291 Página } 285\end{array}$ 
Figura 4 - Etapas de execução dos projetos. A) Parte da equipe do projeto em trabalho de pesquisa de campo; B) Confecção de tintas de solos coletados no município de Ferreira Gomes-Ap;C) Realização da oficina "Conversando com os solos", com alunos dos cursos de Licenciatura, Bacharelado e Pós-Graduação em

Geografia da UNIFAP; D) Coleta de material para análise de degradação dos solos em áreas de acesso aos geomorfossítios e sítios arqueológicos; E) Apresentação de painel interpretativo em workshop sobre geodiversidade de Ferreira Gomes-Ap, para professores de escolas do município.

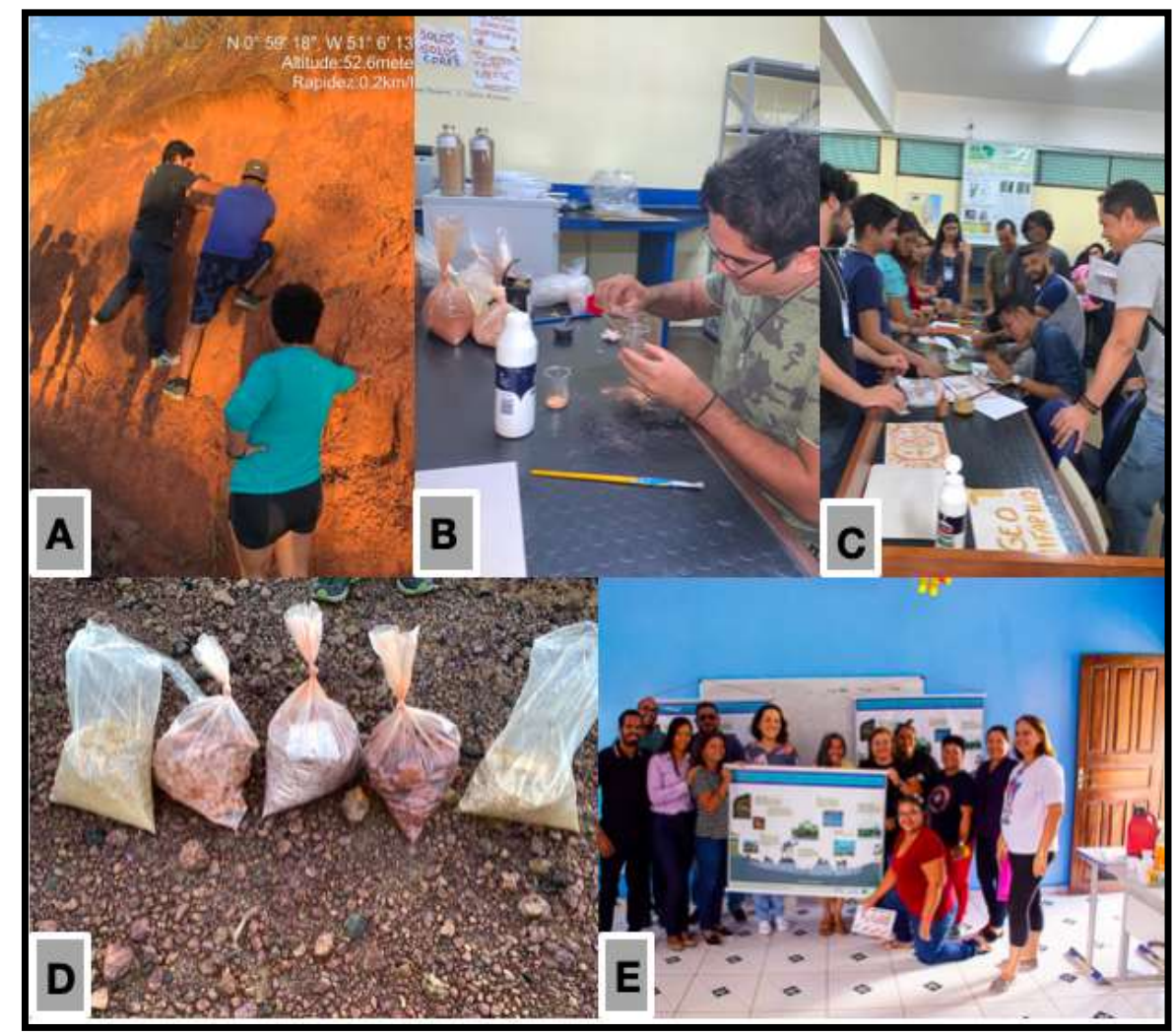

Fonte - Arquivos dos projetos mencionados, 2019.

Ainda no estado do Amapá levantou-se o registro de uma projeto de pesquisa denominado: "Curso de campo: biodiversidade e geodiversidade amazônica", coordenado pela professora Débora Regina dos Santos Arraes, da Universidade do Estado do Amapá. O projeto visa, através de parcerias institucionais, desenvolver estudos por meio de curso de campo com aulas, pesquisas e coletas de material em diferentes áreas fisiográficas, visando integrar o conhecimento e experiências sobre o ambiente natural (AMAPÁ, 2020).

Outro projeto de pesquisa identificado no estado do Amapá tem como título: "Potencialidades para o desenvolvimento do geoturismo no município do Oiapoque - Ap", e encontra-se sob coordenação do professor Dr. José Mauro Palhares, da Universidade Federal do Amapá. O projeto foi cadastrado no ano de 2017 e busca fazer o levantamento do potencial geoturístico do município, a partir do estudo de referências sobre a geodiversidade do local, trabalhos de campo e produção de mapas.

No estado do Amazonas, registrou-se um projeto de extensão, executado entre 2018 e 2019, sob a coordenação do professor Dr. Raimundo Humberto Cavalcante Lima, ligado ao departamento de geociências da Universidade Federal do Amazonas (UFAM). O nome do projeto é "As pedras que sinalizam" e sua contribuição é democratizar o conhecimento de geociências através da exposição de minerais, rochas e fósseis, promovendo, assim, um diálogo com a comunidade a partir da temática da geodiversidade.

No estado do Pará é importante mencionar as contribuições para a temática a partir dos projetos de pesquisa e extensão intitulados: "Geografia do Turismo" e "Roteiros Geo-turísticos em Belém do Pará", coordenados pela professora Dra. Maria Goretti da Costa Tavares, professora da Universidade Federal do Pará (UFPA). A partir dos ref eridos projetos o geoturismo é abordado em uma perspectiva histórica, cultural e patrimonial das paisagens construídas em diferentes contextos históricos no espaço urbano

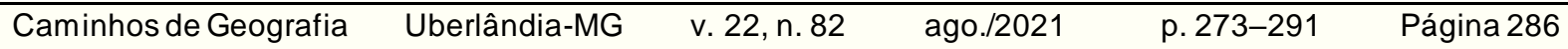


de Belém. Verifica-se que, embora os projetos não estejam voltados ao Patrimônio Natural, o foco é o Patrimônio Cultural, material e imaterial. Conforme artigo publicado por Tavares (2018), os roteiros valorizam o patrimônio cultural local como forma de reforçar a importância do direito a cultura, ao patrimônio e a cidade. Sugere-se, no presente artigo, que o patrimônio imaterial em espaços urbanos, onde o principal sujeito de transformação das paisagens é o homem, pode registrar a presença de elementos da geodiversidade por meio dos materiais de origem de construções, por exemplo.

Outros dois projetos de pesquisa ativos voltados aos estudo da geodiversidade no estado do Pará, intitulam-se: "Geodiversidade, potencial geoturístico e geoconservação da ilha de Mosqueiro, BelémPa" e "Roteiro Geoturístico na ilha de Mosqueiro, Belém-Pa", ambos são coordenados pela professora Dra. Luciana Martins Freire, da UFPA, campus de Ananindeua. Os projetos se complementam, uma vez que o primeiro objetiva fazer um levantamento do patrimônio geológico na área de estudo e a partir da avaliação dos interesses científico, ambiental e cultural contribuir com o reconhecimento de sítios geológicos. E, assim, através do projeto sobre os roteiros geoturísticos, utilizar os geossítios com interesse turístico e educacional para analisar as potencialidades geoturísticas e construir o roteiro.

Em Santarém, no oeste do Pará, o Projeto "Roteiros Santarenos: Geologia, História e Turismo" de pesquisa e extensão foi idealizado e coordenado pela Prof. Ms. Deize de Souza Carneiro iniciou em 2011, via Universidade Federal do Oeste do Pará (UFOPA). O objetivo do projeto foi contribuir com a educação patrimonial e ambiental da comunidade acadêmica e localidades do entorno de Santarém, por meio de excursões geológicas visando a conservação do Patrimônio Geológico da região oeste do Pará. Em 2014 a UFOPA iniciou o projeto de extensão "Patrimônio Histórico Arquitetônico e Geológico: Iniciativas de Divulgação e Preservação através da Educação" com coordenação da Prof. Dra. Fernanda Souza do Nascimento. Este projeto prevê excursões no centro da cidade para apresentar informações históricas e do contexto geológico do local (figura 5).

Figura 5 - A) Detalhes de utilização de lupa para verificar macroscopicamente os minerais da pia da água benta na Igreja Matriz de Nossa Senhora da Conceição; B) Excursão "Entre a cidade e o rio" com ênfase em explanar sobre a geomorfologia fluvial e a relação da cidade de Santarém com as inundações sazonais; C) Momento de explanação sobre a história de Santarém durante a excursão "Patrimônio histórico"; D) Chegada em na llha do Amor em Alter-do-Chão para o início da excursão "Geologia de Santarém".

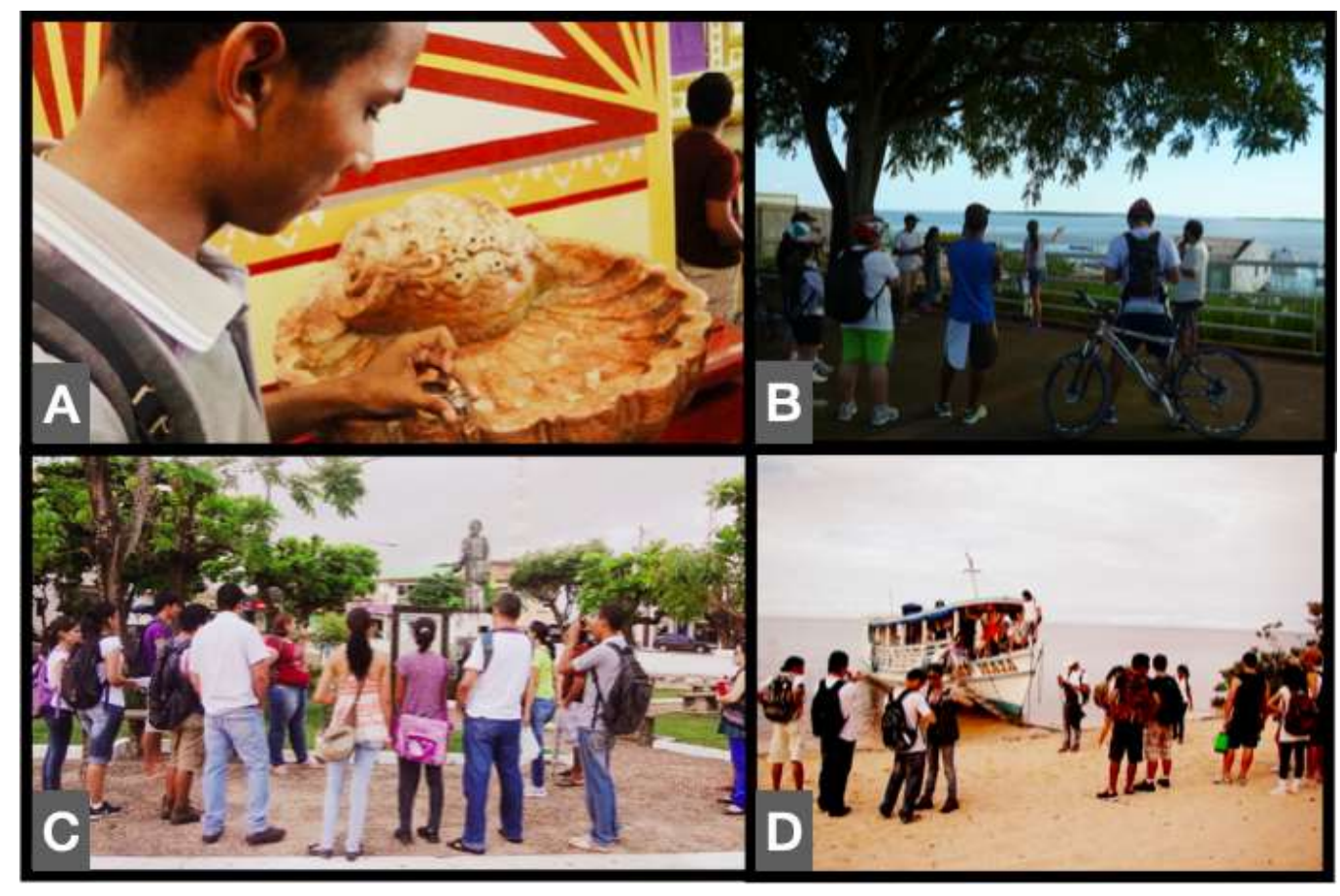

Fonte - Acervo Projeto Roteiros Santarenos: Geologia, História e Turismo (2012, 2013).

Para o estado de Roraima identificou-se um projeto de pesquisa desenvolvido entre os anos de 2016 e 2018, pela professora Dra. Márcia Teixeira Falcão, intitulado: "Estudo do patrimônio geomorfológico

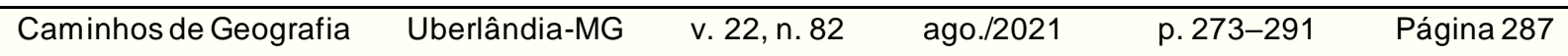


no entorno da sede do município de Uiramutã - RR", cujo objetivo foi estudar este patrimônio com a finalidade de conhecê-lo para viabilizar a atividade turística. Identificou-se, através do currículo Lattes da pesquisadora, outros projetos de natureza similar e, inclusive, voltados para uma temática importante nos estudos de geoconservação que é a divulgação do patrimônio natural visando a sensibilização ambiental.

\section{CONSIDERAÇÕES FINAIS}

As informações disponibilizadas a partir da SIGEP, do GEOSSIT, das propostas de geoparques e dos projetos de pesquisa, ensino e extensão voltados a geoconservação do meio abiótico do Patrimônio Natural, são instrumentos de promoção e valorização da geodiversidade, e ilustram o atual cenário das novas formas de conservação para a Amazônia.

É relevante o papel da pesquisa a partir das universidades e sua contribuição para alimentar os sistemas SIGEP e GEOSSIT, além do suporte a elaboração de propostas de criação de geoparques. Enquanto instituição, e através de suas atividades sistemáticas, as universidades podem atuar através da produção de conhecimento científico, do ensino e da extensão e permitir além do levantamento de informações a sua popularização, construindo diagnósticos, valo rizando o ensino, a produção científica e, principalmente, adaptando a linguagens acessíveis para levar a informação para a comunidade.

Concluiu-se que o cenário de valorização e geoconservação na Amazônia mostra que a maioria dos estados tem trabalhos ou projetos sobre o tema, e a perspectiva é de que isso seja divulgado, que multipliquem-se os trabalhos dentro da temática, ainda que o fomento esteja extremamente diminuído.

Não menos importante é a atuação de interesses em nível governamental e dos setores produtivos para que os desafios para conservação da geodiversidade na Amazônia, através do apoio logístico e financeiro, diálogo entre pesquisadores e instituições, trabalho em conjunto, seja no curto prazo superados.

\section{AGRADECIMENTOS}

À Fundação de Amparo a Pesquisa do Estado do Amapá (FAPEAP), pelo financiamento de projeto de pesquisa e à Pro-Reitoria de Ações Comunitárias da Universidade Federal do Amapá (PROEAC/UNIFAP), pelo auxílio ao projeto de extensão.

\section{REFERÊNCIAS}

AMAPÁ. UNIVERSIDADE FEDERAL DO AMAPÁ. Curso de Campo: Biodiversidade e Geodiversidade Amazônica. Disponível em:

http://www2.ueap.edu.br/pagina/projetos_de_pesquisa_registrados.html Acesso em: 09 de julho de 2020.

ANDRADE, M.; ANDRADE, M. CARNEIRO, D. Geodiversidade e Geoturismo Urbano: estudo de caso em Santarém (PA). Revista Turydes: Turismo y Desarrollo, n. 22, junho, 2017.

BARROS, J.; FILHO, J.; FREITAS, L. Geoparques do Brasil. Geoparque Vale das Águas Maranhão - Proposta. Serviço Geológico do Brasil - CPRM. 2019. 88p. Disponível em: http://rigeo.cprm.gov.br/jspui/handle/doc/20813 Acesso em: 11 de junho de 2020.

BRASIL. Lei n. 5.173, de 27 de outubro de 1966. A Amazônia para ef eitos desta lei, abrange a região compreendida pelos Estados do Acre, Pará e Amazonas, pelos Territórios Federais do Amapá, Roraima e Rondônia, e ainda pelas áreas do Estado de Mato Grosso a norte do paralelo 16을 do Estado de Goiás a norte do paralelo $13^{\circ}$ e do Estado do Maranhão a oeste do meridiano de 44‥Disponível em: http://www.planalto.gov.br/ccivil_03/leis/L5173.htm Acesso em: 06 de julho de 2020.

Lei complementar n. 31, de 11 de outubro de 1977. A Amazônia, a que se refere o artigo $2^{\circ}$ da lei $n^{\circ}$ 5.173, de 27 de outubro de 1966, compreenderá também toda a área do Estado de Mato

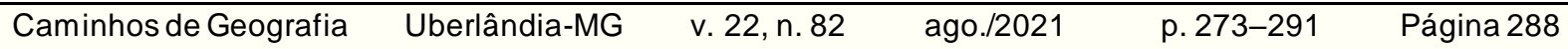


Grosso.Disponível em: http://www.sudam.gov.br/index.php/ouvidoria/58-acesso-a-informacao/86legislacao-da-amazonia Acesso em: 06 de julho de 2020.

Sistema Nacional de Unidades de Conservação da Natureza - SNUC, 2000. Disponível em: <www.planalto.gov.br/ccivil_03/leis/19985.htm> Acesso em: 11 de dezembro de 2020.

BRILHA, J. Património geológico, geoconservação: a conservação da natureza na sua vertente geológica. Braga, Portugal: Palimage, 2005. 190p.

BRILHA, J.Inventory and Quantitative Assessment of Geosites and Geodiversity Sites: a review. Geoheritage, v.8, n.2, p.119-134, 2016. https://doi.org/10.1007/s12371-014-0139-3

BRILHA, J.; GRAY, M.; PEREIRA, D.; PEREIRA, P. Geodiversity: An integrative review as a contribution to the sustainable management of the whole of nature. Environmental Science and Policy, v. 86, p. 19 - 28, 2018. https://doi.org/10.1016/j.envsci.2018.05.001

COSTA, N.; OLIVEIRA, F. Trilhas: "Caminhos" para o geoturismo, a geodiversidade e a geoconservação. In: GUERRA, A.; JORGE, M. (Org.) Geoturismo, geodiversidade e geoconservação: abordagens geográficas e geológicas. São Paulo: Oficina de textos, 2018. p. 201227.

ESPIRITO SANTO, C. Geoconservação no estado do Amapá: uma contribuição metodológica do "Valor de Conservação do Solo" para a avaliação da geodiversidade no médio curso do rio Araguari. Tese (Doutorado em Geografia) - Rio de Janeiro: UFRJ. 2018. 203p.

ESPIRITO SANTO, C; GUERRA, A.; SZLAFSZTEIN, C.; COSTA, J. A quantificação da geodiversidade e o potencial para o geoturismo em geomorfossítios no médio curso do rio Araguari, estado do Amapá. Anais do XII Simpósio Nacional de Geomorfologia. 2018. Disponível em: https://www.sinageo.org.br/2018/trabalhos/5/5-94-28.html Acesso em: 06 de julho de 2020.

FALCÃO, M.; SILVA, T.; SOUZA, J. Geodiversidade e geoturismo: estudo das potencialidades do município do Uiratumã - Roraima. Anais do XI Encontro de Iniciação Científica - Estácio da Amazônia. 2019. p. 43 - 54. Disponível em:

http://periodicos.estacio.br/index.php/pkcroraima/article/download/7649/47966445 Acesso em: 09 de julho de 2020.

FERREIRA, A. Geomorfologia, geodiversidade e análise da fragilidade ambiental das paisagens do parque estadual Serra Ricardo Franco, MT-Brasil. Tese (Doutorado em Geografia) - São Paulo: USP. 2014. 168p.

FIGUEIREDO, S.; GORAYEB, P. Análise geológica, geomorfológica e turística do Parque estadual da serra dos Martírios-Andorinhas: potencial para o Geoturismo. Campinas, SeTur/SBE. Pesquisas em Turismo e Paisagens Cársticas, 2(1), fevereiro, 2009, p. 41 - 55.

GARCIA-CORTÉS, A.; URQUÍ, L. Documento Metodológico para la elaboracion del inventario espanñol de lugares de interés geológico (IELIG). Madrid: Instituto Geológico y Minero de España, 2009, 64p.

GRAY, M. Geodiversity: valuing and conserving abiotic nature. Chichester: Wiley-Blackwell, 2004, 434p.

HOSE, T. 3G's for Modern Geotourism. Geoheritage, v. 4, p. 7-24, 2012.

https://doi.org/10.1007/s12371-011-0052-y

JORGE, M. O papel das comunidades locais, sua importância e os novos desafios acerca da sustentabilidade ambiental. In: GUERRA, A.; JORGE, M. (Org.) Geoturismo, geodiversidade e geoconservação: abordagens geográficas e geológicas. São Paulo: Oficina de textos, 2018. p. 5180.

JUNIOR, H.; MORAES, J.; PAULA, T. Geoparque Chapada dos Guimarães. Proposta. n: Geoparques do Brasil - Propostas. SCHOBBENHAUS, C.; SILVA, C. (Org.), Serviço Geológico do Brasil - CPRM. v.1, 2012. p. 285 - 316. Disponível em:

http://rigeo.cprm.gov.br/bitstream/doc/17167/1/guimaraes.pdf Acesso em: 06 de julho de 2020. 
KUHN, C.; TOBIAS, T. Roteiro geoturístico de Chapada dos Guimarães: uma proposta de educação em geociências. Ciência e Sustentabilidade - CeS | Juazeiro do Norte, v. 3, n. 1, p.74-93, 2017.

LOPES, L.S.O; ARAÚJO, J.L.L. Princípios e estratégias de geoconservação. OBSERVATORIUM: Revista Eletrônica de Geografia, v.3, n.7, p. 66-78, out. 2011.

LUZARDO, R. Geoparque Cachoeiras do Amazonas - proposta. In: Geoparques do Brasil Propostas. SCHOBBENHAUS, C.; SILVA, C. (Org.), Serviço Geológico do Brasil - CPRM. v.1, 2012. p. 39 - 58. Disponível em: http://rigeo.cprm.gov.br/handle/doc/17166 Acesso em: 11 de junho de 2020.

MANSUR, K. Patrimônio geológico, geoturismo e geoconservação: uma abordagem da geodiversidade pela vertente geológica. In: GUERRA, A.; JORGE, M. (Org.) Geoturismo, geodiversidade e geoconservação: abordagens geográficas e geológicas. São Paulo: Oficina de textos, 2018. p. $01-49$.

MARCELINO, G.; ALVARENGA, O.; MATHIAS, D. A importância do geossítio Cidade de Pedra para o ensino de geografia física: parque nacional da Chapada dos Guimarães-MT. In: Anais do XVIII Simpósio Brasileiro de Geografia Física Aplicada: geografia física e as mudanças globais. Universidade Federal do Ceará. 2019. p. 1 - 5. Disponível em:

http://www.editora.ufc.br/images/imagens/pdf/geografia-fisica-e-as-mudancas-globais/1316.pdf Acesso em: 06 de julho de 2020.

MEIRA, S.; SILVA, E. Projeto Geoparques do Brasil e geomorfologia: uma análise dos geomorfossítios nas propostas nordestinas. In: ANAIS do XII SINAGEO - Simpósio Nacional de Geomorfologia - UGB - União da Geomorfologia Brasileira. 2018. Disponível em: https://www.sinageo.org.br/2018/trabalhos/5/5-87-1059.html Acesso em: 11 de junho de 2020. MEIRA, S.; ARNEDO, M.; NASCIMENTO, M.; SILVA, E. Potencial educativo del patrimonio geológico: estudio sobre el geositio sítio do Bosco. Geosaberes, Fortaleza, v. 11, p. 162-179, 2020. Doi: 10.26895/geosaberes.v11i0.870. https://doi.org/10.33809/2447-4606.31201774-93

MONOSSO, F.; ONDICOL, R. Geodiversidade: considerações sobre quantificação e avaliação da distribuição espacial. Anuário do Instituto de Geociências. UFRJ, v. 35 - 1, p. 90 - 100, 2012. https://doi.org/10.11137/2012190100

MOREIRA, J.; VALE, T. Geoparks: educação, conservação e sustentabilidade. In: GUERRA, A.; JORGE, M. (Org.) Geoturismo, geodiversidade e geoconservação: abordagens geográficas e geológicas. São Paulo: Oficina de textos, 2018. p. 81-110.

MUNIZ, G.; CASTRO, C. A produção do espaço e o turismo em Carolina - Maranhão, Brasil. Revista Interespaço, v.4, n.15, 82-105, 2018. https://doi.org/10.18764/2446-6549.v4n15p82-105

PALHARES, J.; GUERRA, A. Potencialidades no município de Oiapoque, Amapá, para o desenvolvimento do geoturismo. Espaço Aberto, PPGG - UFRJ, V. 6, N.2, p. 51-72, 2016. https://doi.org/10.36403/espacoaberto.2016.5219

PEREIRA, R. G. F de A.; RIOS, D. C.; GARCIA, P. Geodiversidade e patrimônio geológico: ferramentas para a divulgação e ensino das geociências. TERRÆE DIDATICA 12-3,201, p. 196208, 2016. Doi: http://dx.doi.org/10.20396/td.v12i3.8647897.

https://doi.org/10.20396/td.v12i3.8647897

PEREIRA, P. Patrimônio geomorfológico: conceptualização, avaliação e divulgação. Aplicação ao Parque Natural de Montesinho. Tese (Doutorado em Ciências) - Braga: Universidade do Minho. 2006. 370p.

PEREIRA, P.; PEREIRA, D.; ALVES, C. Avaliação do Patrimônio Geomorfológico: proposta de metodologia. In: Publicações da Associação Portuguesa de Geomorfólogos, volume V. Apgeom, Lisboa, 2007. p.235 - 247.

PEREIRA, R. G. F. de A. Geoconservação e desenvolvimento sustentável na Chapada Diamantina (Bahia- Brasil). Tese (Doutorado em Geologia) - Braga: Universidade do Minho. 2010. $318 \mathrm{p}$.

$\begin{array}{lllll}\text { Caminhos de Geografia } & \text { Uberlândia-MG } & \text { v. 22, n. } 82 & \text { ago./2021 } & \text { p. 273-291 }\end{array}$ Página 290



Jucilene Amorim Costa

PEREIRA, R. G. F de A.; BRILHA, J. Proposta de quantificação do património geológico da Chapada Diamantina (Bahia, Brasil). Anais do VIII Congresso Nacional de Geologia, 2010. 4p.

REIS, J.; FARIA, I.; FRAXE, T. Geoconservação e Geoturismo na Amazônia: contexto e perspectivas no Geoparque Cachoeiras do Amazonas. Revista Turismo em Análise, v. 31, n. 1, p. 50-76, 2020. https://doi.org/10.11606/issn.1984-4867.v3111p50-76

RIBEIRO, W. A ordem ambiental internacional. São Paulo: Contexto, 2001. 176p.

SALDANHA, D.; MEDEIROS, M.; SANTOS, N.; COSTA, D. Patrimônio natural e educação ambiental: travessias entre a ciência e o ensino. Revista da casa da geografia de sobral, sobral/ce, v. 21, n. 2, dossiê: estudos da geografia física do nordeste brasileiro. p. 1154-1164, 2019. https://doi.org/10.35701/rcgs.v21n2.549

SANTOS, V.; JACOBI, P. Educação, ambiente e aprendizagem social: metodologias participativas para geoconservação e sustentabilidade. Rev. bras. Estud. pedagog., Brasília, v. 98, n. 249. p. 522-539, 2017. DOI: http://dx.doi.org/10.24109/2176-6681.rbep.98i249.2758. https://doi.org/10.24109/2176-6681.rbep.98i249.2758

SERVIÇO GEOLÓGICO DO BRASIL. SGB/CPRM. GEOSSIT. Disponível em: https://www.cprm.gov.br/geossit/ Acesso em: 15 de junho de 2020a.

SIGEP. Disponível em: http://sigep.cprm.gov.br Acesso em: 15 de junho de $2020 \mathrm{~b}$.

SIGEP. Propostas aprovadas pela SIGEP. Sítios não publicados. Disponível em:

http://sigep.cprm.gov.br/Vol_lll/318_Sitios_Nao_Publicados.pdf Acesso em: 15 de junho de 2020c. p. $316-325$.

SILVA, J.; AQUINO, C. Ações geoeducativas para divulgação e valorização da geodiversidade e do geopatrimônio. Geosaberes, Fortaleza, v. 9, n. 17, p. 1-12, 2018. https://doi.org/10.26895/geosaberes.v9i17.617

SILVA, J. Avaliação da Diversidade de Padrões de Canais Fluviais e da Geodiversidade na Amazônia - Aplicação e Discussão na Bacia Hidrográfica do Rio Xingu. Tese (Doutorado em Geografia) - São Paulo: USP. 2012. 277p.

SILVA, J.; PEREIRA, D.; AGUIAR, A.; RODRIGUES, C. Geodiversity assessment of the Xingu drainage basin. Journal of Maps. v. 9, n. 2, p. 254 - 262, 2013.

SILVA, J.; RODRIGUES, C. Morfologia fluvial como indicador de geodiversidade: Exemplos de rios brasileiros. Revista de Geografia. Recife: UFPE - DCG/NAPA, v. especial VIII SINAGEO, n. 3, 2010. https://doi.org/10.1080/17445647.2013.775085

TAVARES, M. Patrimônio e cidade: uma leitura geográfica da cidade de Belém do Pará. Revista Geografar-Curitiba, v.13, n.1, p.162-180, 2018. https://doi.org/10.5380/geografar.v13i1.60269 